Journal of Applied Pharmaceutical Science Vol. 5 (11), pp. 135-145, November, 2015

Available online at http://www.japsonline.com

DOI: $10.7324 / \mathrm{JAPS} .2015 .501123$

ISSN 2231-3354 (cc) BY-NC-SA

\title{
Fabrication, Physicochemical Characterization and Evaluation of In vitro Anticancer Efficacy of a Novel pH Sensitive Polymeric Nanoparticles for Efficient Delivery of Hydrophobic Drug against Colon Cancer
}

\author{
Manikandan Mahalingam, Kannan Krishnamoorthy \\ Department of Pharmacy, Annamalai University, Annamalai Nagar, Chidambaram, India.
}

\section{ARTICLE INFO}

Article history:

Received on: 15/09/2015

Revised on: 05/10/2015

Accepted on: 04/11/2015

Available online: 27/11/2015

Key words:

Camptothecin,

nanoprecipitation, anticancer

activity, stability studies.

\begin{abstract}
Objective: The present investigation was aimed to overcome the limitations and to enhance the incorporation of the hydrophobic drug into polymeric nanoparticles and characterize the prepared nanoparticles and also to evaluate the in vitro anticancer efficacy of prepared nanoparticles.

Method: Nanoprecipitation method was used to prepare plain and hydrophobic drug (Camptothecin) loaded polymeric nanoparticles. Prepared nanoformulations were evaluated for average particle size, particle size uniformity, surface area, zeta potential, surface morphology, drug content, encapsulation efficiency, drug loading, in vitro release, anticancer activity and stability studies at long term and accelerated storage conditions.

Results: Plain and Camptothecin loaded polymeric nanoparticles were successfully prepared by nanoprecipitation method using stirring technique. Prepared Camptothecin encapsulated polymeric nanoparticles were (a) spherical in shape with size $<100 \mathrm{~nm}$, displayed excellent uniformity with $<0.3$ and zeta potential $>20$ $\mathrm{mV}$; (b) showed $>95 \%$ release in colonic environment; (c) demonstrated enhanced anticancer activity than pure Camptothecin; and (d) extremely stable at both long term and accelerated storage conditions.

Conclusion: In summary, the investigation concluded that the prepared Camptothecin encapsulated polymeric nanoformulations may be considered as an attractive and promising formulation which significantly overcome the limitations of Camptothecin and synergistically enhance its anticancer activity.
\end{abstract}

\section{INTRODUCTION}

Colon cancer is a multifactorial disease and has emerged as a major public hazard (Giftson et al., 2001). It is the third most common malignancy and second most common cause of cancer with more than 1.4 million new cases and over half a million death worldwide each year (Terzic et al., 2010). Surgery, chemotherapy and radiotherapy are the currently available predominant therapeutic strategies for the treatment of colon cancer. Among the modalities, chemotherapy is the major remedial approach for the treatment of localized and metastasized cancer (Xiao et al., 2015). Well-designed drug delivery vehicle

* Corresponding Author

Email:egkkannan@yahoo.co.in is need to be developed to enable cancer chemotherapy that fundamentally enhances the therapeutic efficacy by minimizing drug release in undesirable sites (Eun-Kyung et al., 2013). Furthermore, oral colonic drug delivery is convenient to administers and painless to patients when compared with surgery and radiotherapy (Wang et al., 2013). Investigations revealed that encapsulation of anticancer drug into colloidal drug delivery vehicle minimize the tissue distribution and improves therapeutic performance (Averineni et al., 2012). Hydrophobic drug compounds account for $40 \%$ of the new drug candidates under FDA review (Kumar and Prud'homme, 2009). Many therapeutic anticancer drugs are limited in their clinical applications because of their toxicities and low solubility in aqueous media (Eun-Kyung Lim et al., 2013). 
For instance, Camptothecin (CPT), is one of the distinguished antineoplastic agent reported to possess promising anticancer activity that targets the nuclear enzyme: DNA topoisomerase I and inhibits the relegation of the cleaved DNA stand, results in tumor cell death. However, the clinical application of Camptothecin is hindered by its poor aqueous solubility and severe systemic toxicities (Manikandan and Kannan, 2015). Solubility of the active ingredient is a major pharmaceutical concern in developing a novel drug delivery system and is also a key parameter when it comes to screening, drug designing, formulating and improving the modeling of oral bioavailability of the drug (Averineni et al., 2012, Prakash et al., 2008). Delivering the drug precisely and safely to its target site at the right period of time to have a controlled release and achieve the maximum therapeutic effect remains a yardstick in the design and development of novel drug delivery systems (Mishra et al., 2010).

Nanotechnology is a rapidly expanding field and the novel properties of nanomaterial's offer great promise to provide new technological breakthroughs (Gregory Morose, 2010). Nanomaterial based drug delivery systems have received attention in overcoming the drawbacks. In particular, the use of nanomaterial's as anticancer drug nanovectors is expected to overcome some of the issues inherent to conventional chemotherapy, including the poor pharmacokinetic profiles of the anticancer drugs and their lack of tumor specificity (Emilie Secret et al., 2013).

Nanoparticulate systems are new tools that promise a revolution in the field of drug delivery. According to the OstwardFreundlich and Noyes-Whitney equation, the saturation solubility and dissolution rate of a drug can be increased by reducing the particle size to increase the interfacial surface area (Ji-Yao Zhang et al., 2006). Nanocarriers, on account of their higher ratio of surface area to volume, show improved pharmacokinetics and biodistribution of therapeutic agents and thus minimize toxicity by their preferential accumulation at the target site. They improve the solubility of hydrophobic drug and render them suitable for oral administration (Alexis et al., 2008). Conventional technique to increase the bioavailability of these hydrophobic drugs is by formulation nanoparticles with high surface-to-volume ratios (Kumar and Prud'homme, 2009).

Nanoparticles (NPs) are customized drug delivery vectors capable of preferentially targeting large doses of chemotherapeutic agents into malignant cells while sparing the healthy cells (Sinha et al., 2006). Generally, nanoparticles that have a mean diameter of approximately $100 \mathrm{~nm}$, bearing a neutral and hydrophilic surface, exhibit prolonged blood circulation and an increased level of tumor delivery (Catarina et al., 2010). Nanoparticle system with maximal drug loading and a high entrapment efficiency will reduce the quantity of carrier required for the administration of sufficient amount of drug to the target site as well as drug wastage during formulation (Thirumala Govender et al., 1999).

The delivery of an anticancer drug to the target tissue can be achieved by NPs primarily in two ways: passive and ligand- based targeting. Passive targeting approach exploits the pathophysiological conditions, such as leaky vasculature, $\mathrm{pH}$, temperature and surface charge surrounding the tumor for specific delivery of NPs (Prabhu et al., 2015). While nanoparticles tend to passively accumulate in tumor tissue due to the enhanced permeation and retention (EPR) effect, which is ascribed to enhanced vascular permeability in tumors, active endocytosis of nanoparticles targeting cancer cells is equally desired in order to further increase the concentration of the anticancer drug intracellularly and to limit its toxic effects in normal tissue (Torchilin, 2011).

The propensity of nanoscale materials (compared to single small molecules) to accumulate in a tumor through the EPR effect provides many possibilities to design effective drug delivery nanosystems that vectorize poorly water soluble toxic anticancer drug to tumor sites (Danhier et al., 2010). Vectorization of the hydrophobic alkaloid Camptothecin using polymeric nanoparticle is a highly promising route to avoid the drawbacks of this drug and develop a novel delivery system (Emilie Secret et al., 2013).

Polymeric nanoparticles (PNPs) are solid colloidal systems in which the therapeutic agent is dissolved, entrapped, encapsulated or adsorbed onto the constituent polymer matrix (Prabhu et al., 2015). Polymeric nanoparticles are biodegradable and biocompatible and have been adopted as a preferred method for nanomaterial drug delivery. The polymer matrix prevents drug degradation and may also provide management of drug release from these nanoparticles. The surface properties of these polymeric nanoparticles are also a vital component of their targeting characteristics (Faraji and Wipf, 2009). Drug delivery systems can be designed to release drugs triggered by environmental parameters such as $\mathrm{pH}$, enzymes, and temperature. $\mathrm{pH}$ dependent solubility would significantly assists in improving the modeling of oral bioavailability of the drug (Eun-Kyung Lim et al., 2013).

Methods of preparation of PNPs fall into two major classes: one deals with the polymerization of monomers (e.g., emulsion and dispersion polymerization), whereas the other essentially involves dispersion of polymers (e.g., salting out, emulsification-diffusion and nanoprecipitation) (GalindoRodriguez et al., 2004). In order to produce small and low polydisperse nanoparticle population, the nanoprecipitation method developed by Fessi et al., in 1989 is one of the most easy and reproducible technique and has been widely used by several research group to prepare polymeric nanoparticles (Thirumala Govender et al., 1999, Eliana Leo et al., 2004). This method is basically applicable to hydrophobic drugs due to the miscibility of the solvent with the anti-solvent (Jose Mario Barichello et al., 1999).

The present investigation was aimed to overcome the limitations and to enhance the incorporation of the hydrophobic drug into polymeric nanoparticles and characterize the prepared nanoparticles and also to evaluate the in vitro anticancer efficacy of prepared nanoparticles. 


\section{MATERIALS AND METHODS}

\section{Materials}

Camptothecin was commercially purchased from S.M Herbals, India. $\beta$-cyclodextrin and poloxamer (Grade 188) were procured from Sigma Aldrich, India. Poly (methacylic acid-comethyl methyacrylate) was obtained from Evonik Industries, India. Dimethyl sulphoxide and propanol were obtained from E-Merck specialities Pvt. Ltd., India. 3-(4,5-dimethyl thiazol-2-yl) -5diphenyl tetrazolium bromide (MTT), Fetal Bovine serum (FBS), Phosphate Buffered Saline (PBS), Dulbecco's Modified Eagle's Medium (DMEM) and Trypsin were obtained from Sigma Aldrich Co, USA. EDTA, Glucose and antibiotics from Hi-Media Laboratories Ltd., India. All other chemicals and reagents used were of analytical grade and used without further purification.

\section{Fabrication of plain and Camptothecin loaded polymeric nanoparticles}

Processing of hydrophobic drug into polymeric nanoparticle requires a conventional technique. Nanoprecipitation is the process with an attractive processing scheme based on rapid mico-mixing of two streams: solvent and anti-solvent. The solvent stream is composed of hydrophobic drug and copolymer dissolved in water miscible organic solvent and water containing surfactant is generally used as an anti-solvent. This technique is a rapid and direct process, which can be performed in ease. The particle size of the drug decreases with the increase in the stirring rate (Kumar and Prud'homme, 2009, Ji-Yao Zhang et al., 2006). Camptothecin loaded polymeric nanoparticles were prepared by a novel nanoprecipitation technique.

Briefly, about $100 \mathrm{mg}$ of poly (Methacyclic acid-comethyl-methyacrylate) polymer with and without (plain nanoparticles) $10 \mathrm{mg}$ of Camptothecin were dissolved in $10 \mathrm{ml}$ of dimethyl sulphoxide. The prepared organic phase was transferred at once into $500 \mathrm{ml}$ beaker containing $50 \mathrm{mg}$ of $\beta$-cyclodextrin, $100 \mathrm{mg}$ of poloxamer 188 and $20 \mathrm{ml}$ of distilled water under mechanical stirring (Remi, India) at $500 \mathrm{rpm}$. Polymeric nanoparticles were formed spontaneously but the stirring process is continued for 50 mins to aid the size reduction and to evaporate the residual solvents (Table 1). The fabrication experiments were performed in triplicate. Prepared polymeric nanoformulations were stored at room temperature for one month to identify any aggregation and post-formulation degradation.

\section{Physicochemical characterization of prepared polymeric nanoparticles \\ Average Particle size, Particle size uniformity, Surface area and Zeta potential}

Prepared plain and Camptothecin loaded polymeric nanoparticles were characterized for average particle size, particle size uniformity, surface area, as these parameters decides the performance such as solubility, dissolution, stability, circulation half-life, drug release, cellular uptake and bio-distribution (Manikandan and Kannan, 2015, Xie and Smith, 2010).

The average particles size, particle size uniformity and surface area of prepared polymeric nanoparticles were measured based on quasi-elastic light scattering principle using mastersizer (Malvern Instrument, UK). Briefly, prepared Camptothecin loaded polymeric nanoparticle formulations was added drop wise into the water maintained in the sample dispersion unit of particle size analyzer, where the nanoparticles scattered using simple shaft pump an stirrer and re-circulated continuously around the measurement zone of particle size analyzer. The experiments were performed in triplicate (Mohanty and Sahoo, 2010).

Zeta potential of the prepared polymeric nanoparticles was measured using zetasizer (ZEN3600, Malvern). The zeta potential is commonly used to characterize and measure the surface charge as it plays a significant role in aggregation. Aggregation in nanoparticles in formulation reduces the physical stability of the nanosuspension and leads to decreased oral bioavailability. In a sense, zeta potential represents an index for particle stability. Higher number of either positive or negative charge increase the repulsive interaction leading to stable particles which in turn prevents aggregation. A nanosuspension stabilized by electrostatic repulsion must have a minimum zeta potential of \pm $30 \mathrm{mV}$ (Catarina et al., 2010, Muller et al., 2001). Briefly, about 1 $\mathrm{ml}$ of polymeric nanoparticles was diluted approximately using ultra-pure water (Milli Q Academic Milli Pore). Diluted samples were loaded separately in a disposable zeta cell and measured for zeta potential.

\section{Particle surface morphology analysis}

Prepared plain and Camptothecin loaded polymeric nanoparticles were characterized for surface morphology, as it decides the basic function of particles, degradation, release of drug from polymer, transport of particles in the body and internalization of drug (Xie and Smith, 2010, Mohanty and Sahoo, 2010).

Table 1: Fabrication of Camptothecin loaded polymeric nanoparticles

\begin{tabular}{|c|c|c|c|c|c|c|c|c|c|c|c|}
\hline Trials & $\begin{array}{c}\mathbf{A} \\
(\mathrm{mg})\end{array}$ & $\begin{array}{c}\text { B } \\
(\mathrm{mg})\end{array}$ & $\begin{array}{c}\mathrm{C} \\
(\mathrm{mg})\end{array}$ & $\begin{array}{c}\mathrm{D} \\
(\mathrm{mg})\end{array}$ & $\begin{array}{c}\mathbf{E} \\
(\mathbf{m l})\end{array}$ & $\begin{array}{c}\mathbf{F} \\
(\mathbf{m l})\end{array}$ & $\begin{array}{c}\mathbf{G} \\
(\mathbf{M i n})\end{array}$ & $\begin{array}{c}\mathbf{H} \\
(\mathbf{r p m})\end{array}$ & $\mathbf{J}$ & $\mathbf{K}$ & $\mathbf{L}$ \\
\hline Plain & - & 100 & 50 & 100 & 10 & 20 & 50 & 500 & At once & Or. to Aq. & Blade \\
\hline CPT & 10 & 100 & 50 & 100 & 10 & 20 & 50 & 500 & At once & Or. to Aq. & Blade \\
\hline
\end{tabular}

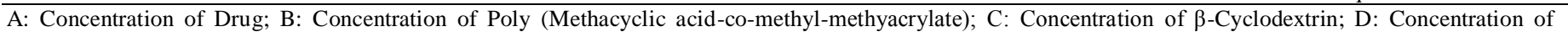

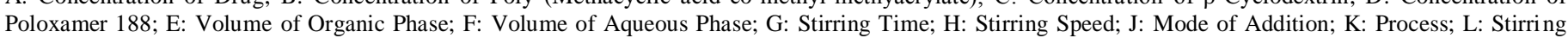

Mode; Or.: Organic Phase; Aq.: Aqueous Phase. 
The morphological examination of the prepared polymeric nanoparticles was performed by Field Emission Scanning Electron Microscopy (FESEM) and Transmission Electron Microscopy (TEM). FESEM (Hitachi SU 660) was used to analyse the morphology by accelerating voltage of $15 \mathrm{kv}$. The spot size in FESEM is smaller than conventional SEM and it can produce very high resolution image. The TEM is also used to analyse the shape of the prepared nanoparticles.

Briefly, the prepared Camptothecin loaded polymeric nanoparticles were dropped onto Formvar-coated copper grids and air dried. The samples were then negatively stained with $1 \%$ uranyl acetate for 10 minutes and air dried again. The samples were then imaged using transmission electron microscope (Hitachi H7500, India) at 20,000 magnifications (Champion et al., 2007, Jung et al., 2002).

\section{Encapsulation efficiency and drug loading estimation}

Camptothecin loaded polymeric nanoformulations were centrifuged using a cooling centrifuge (C-24, Remi) for $45 \mathrm{~min}$ at $19000 \mathrm{rpm}$ at $-20{ }^{\circ} \mathrm{C}$ and supernatant was separated. To $1 \mathrm{ml}$ of supernatant, an equal volume of methanol was added (Verma and Garg, 2005) and sonicated (Ultrasonic cleaner, Lark) for $5 \mathrm{~min}$ followed by filtration through $0.45 \mu \mathrm{m}$ membrane. Samples were analyzed using the developed HPLC methods as mentioned below. Estimated amount of free drugs was expressed as $\mathrm{W}_{\text {free. }}$ The experiments were performed in triplicate.

For the analysis, Shimadzu HPLC system was used with the best chromatographic conditions equipped with $\mathrm{C} 18$ column (ODS $250 \mathrm{~mm}$ X $4.6 \mathrm{~mm}$ with 5 micron pore size, Phenomenax) using a mobile phase combination of $0.5 \% \mathrm{~W} / \mathrm{V}$ of ammonium acetate aqueous solution and acetonitrile $(85: 15, \mathrm{v} / \mathrm{v})$ in an isocratic mode elution with a flow rate of $1 \mathrm{ml} \mathrm{min}^{-1}$ at the column oven temperature of $35^{\circ} \mathrm{C}$ and the samples were analyzed by PDA detector at a wavelength of $368 \mathrm{~nm}$ (Karin Liltorp et al., 2011, Stecanella et al., 2013).

Encapsulation efficiency (EE) and drug loading (DL) were estimated as follows

$\mathrm{EE}(\%)=\frac{\left[\text { Drug Content }\left(\mathrm{W}_{\text {total }}\right)\right]-\left[\text { Drug in the supernatant }\left(\mathrm{W}_{\text {free }}\right)\right]}{\left[\text { Drug Content }\left(\mathrm{W}_{\text {total }}\right)\right]} \times 100$

$\operatorname{DL}(\%)=\frac{\left[\text { Drug Content }\left(\mathrm{W}_{\text {total }}\right)\right]-\left[\text { Drug in the supernatant }\left(\mathrm{W}_{\text {free }}\right)\right]}{\left[\text { Weight of the polymer used in the formulation }\left(\mathrm{W}_{\text {polymer }}\right)\right]} \times 100$

\section{In vitro drug release study}

In vitro drug release of Camptothecin from polymeric nanoparticles was evaluated by dialysis bag diffusion technique. The prepared Camptothecin loaded polymeric nanosuspension (weight equivalent to $10 \mathrm{mg}$ of drug) was placed in cellulose dialysis bag (cutoff 12 000; HIMEDIA, Mumbai, India) and sealed at both ends. The dialysis bag was immersed in the receptor compartment containing dissolution medium maintained at 37 ${ }^{\circ} \mathrm{C} \pm 0.5{ }^{\circ} \mathrm{C}$ with a rotating speed of $100 \mathrm{rpm}$ (Reddy and Murthy, 2005). The release characteristic of Camptothecin from the prepared nanoparticle formulation was investigated using USP dissolution apparatus 2 (Electrolab, Mumbai, India). To achieve simulated gastrointestinal transit condition the release profile of nanoformulation was studied with the dissolution medium of changing $\mathrm{pH}$ at various time intervals. Initially, the dissolution medium was maintained at $\mathrm{pH} 1.2$ with $350 \mathrm{ml}$ of $0.1 \mathrm{~N} \mathrm{HCl}$ for 0 $2 \mathrm{~h}$. At the end of second hour, the $\mathrm{pH}$ of the dissolution medium was raised to 4.5 by the addition of $250 \mathrm{ml}$ of solution composed of $3.75 \mathrm{~g}$ of $\mathrm{KH}_{2} \mathrm{PO}_{4}$ and $1.2 \mathrm{~g}$ of $\mathrm{NaOH}$ and the total volume of dissolution medium was $600 \mathrm{ml}$. At the end of forth hour, $\mathrm{pH}$ of medium was raised to 7.4 by addition of $300 \mathrm{ml}$ of phosphate buffer concentrate $\left(2.18 \mathrm{~g}\right.$ of $\mathrm{KH}_{2} \mathrm{PO}_{4}$ and $1.46 \mathrm{~g}$ of $\mathrm{NaOH}$ in distilled water) (Seema Badhana et al., 2013, Ahmed Abd El-Bary et al., 2012). At predetermined time intervals $5 \mathrm{ml}$ of sample was withdrawn and replaced with fresh dissolution media. The collected samples were filtered through $0.45 \mu \mathrm{m}$ membrane filter (Millipore). After appropriate dilution, the concentration of drug in the sample was analyzed using HPLC.

\section{Kinetic Analysis of Dissolution data}

The data obtained from in vitro release studies were kinetically analysed to find out the mechanism of drug release rate kinetics of dosage form. The obtained data was fitted with zero order, first order, higuchi, hixson-crowell erosion equation, korsmeyer-peppas equation (Kannan et al., 2012, Pandian et al., 2102, Harris Shoaib et al., 2006).

\section{Zero Order Kinetics}

The graph was plotted as cumulative $\%$ drug release Vs time where the drug release rate is independent of its concentration (Hadjiioannou et al., 1993).

Where,

$$
\mathrm{C}=\mathrm{K} \theta \mathrm{t}
$$

$\mathrm{K} \theta=$ Zero order rate constant expressed in units of concentration/time,

$\mathrm{t}=$ Time in hours.

\section{First order Kinetic model}

The graph was plotted as log cumulative \% of drug remaining Vs time, where release rate is concentration dependent (Uday S Rangole et al., 2008).

Where,

$$
\log \mathrm{C}=\log \mathrm{C} 0-\mathrm{Kt} / 2.3030
$$

$\mathrm{C} 0=$ Initial concentration of drug,

$\mathrm{K}=$ First order constant,

$\mathrm{t}=$ Time in hours

\section{Higuchi kinetics}

Higuchi describes the release of drugs from insoluble matrix as a square root of time dependent process based on Fickian diffusion. The graph was plotted as cumulative \% drug released Vs square root of time (Higuchi, 1963).

Where,

$$
\mathrm{Q}=\mathrm{Kt}^{1 / 2}
$$


$\mathrm{K}=$ Constant reflection design variable system,

$\mathrm{t}^{1 / 2}=$ Time in hours.

Hence, drug release rate is proportional to the reciprocal of square root of time. If the plot yields a straight line, and the slope is one then the particular dosage form is considered to follow Higuchi kinetics of drug release.

\section{Hixson-crowell erosion equation}

It describes the drug release with changes in the surface area and the diameter of particles the data were plotted using the Hixson crowell rate equation. The graph was plotted by cube root of $\%$ drug remaining in matrix $\mathrm{Vs}$ time (Hixson and Crowell, 1931).

$$
\mathrm{Q} 0^{1 / 3}-\mathrm{Qt}^{1 / 3}=\mathrm{KHC} \mathrm{t}
$$

Where,

$\mathrm{Qt}=$ Amount of drug released in time $\mathrm{t}$,

$\mathrm{Q} 0=$ Initial amount of drug in tablet,

$\mathrm{KHC}=$ Rate constant for Hixon crowell rate equation.

\section{Korsmeyer-Peppas equation}

To find out the mechanism of drug release, it was further plotted in peppas equation as log cumulative $\%$ of drug released Vs log time (Korsmeyer et al., 1983, Korsmeyer et al., 1986a).

$$
\begin{gathered}
\mathrm{Mt} / \mathrm{M} \alpha=\mathrm{Ktn}, \\
\log \mathrm{Mt} / \mathrm{M} \alpha=\log \mathrm{K}+\mathrm{n} \log \mathrm{t}
\end{gathered}
$$

Where,

$\mathrm{Mt} / \mathrm{M} \alpha=$ Fraction of drug released at time $\mathrm{t}$,

$\mathrm{K}=$ Kinetic rate constant,

$\mathrm{t}=$ Release time,

$\mathrm{n}=$ Diffusion exponent indicative of the mechanism drug release.

This model is used to analyze the release of pharmaceutical polymeric dosage forms when the release mechanism is not known or more than one type of release phenomenon was involved. The $\mathrm{n}$ value could be obtained from slope of the plot of log cumulative \% of drug released Vs log Time (Table 2).

Table 2: Diffusion exponent and solute release mechanism for cylindrical shape.

\begin{tabular}{cc}
\hline Diffusion exponent (n) & Overall solute diffusion mechanism \\
\hline 0.45 & Fickian diffusion \\
$0.45<\mathrm{n}<0.89$ & Anomalous (non-fickian) diffusion \\
0.89 & Case-II transport \\
$\mathrm{n}>0.89$ & Super case-II transport \\
\hline
\end{tabular}

\section{In vitro anticancer activity}

Prepared polymeric nanoformulation was evaluated for anticancer activity using (3-(4,5-dimethylthiazol-2-yl) -2,5diphenyltetrazolium bromide) (MTT) assay on HT-29 (Human colon carcinoma) (Francis and Rita, 1986). Briefly, prepared polymeric nanoformulation was diluted with DMEM supplemented with $10 \%$ inactivated Fetal Bovine Serum (FBS) to obtain a stock solution of $5 \mathrm{mg} / \mathrm{ml}$ concentration, which was sterilized by filtration and finally centrifuged. Serial dilutions
$(1000,500,250,125$ and $62.5 \mu \mathrm{g} / \mathrm{ml})$ were made from the stock solution. About, $0.1 \mathrm{ml}$ of the diluted HT-29 cell suspension (approximately 10000 cells) was added each well of the 96 well microtitre plate. After $24 \mathrm{~h}$, when a partial monolayer was formed, the supernatant was flicked off, washed the monolayer once with medium and $100 \mu \mathrm{l}$ of different test concentrations of test drugs were added. The plates were then incubated at $37^{\circ} \mathrm{C}$ for 3 days in 5 $\% \mathrm{CO}_{2}$ atmosphere and microscopic examination was carried out and observations were noted every $24 \mathrm{~h}$ intervals. After $72 \mathrm{~h}$, the drug solutions in the wells were discarded and $50 \mu \mathrm{l}$ of MTT in PBS was added to each well. The plates were gently shaken and incubated for $3 \mathrm{~h}$ at $37{ }^{\circ} \mathrm{C}$ in $5 \% \mathrm{CO}_{2}$ atmosphere. The supernatant was removed and $100 \mu \mathrm{l}$ of propanol was added and the plates were gently shaken to solubilize the formed formazan. The absorbance was measured using a microplate reader at a wavelength of $540 \mathrm{~nm}$ (Pavan Kumar Bellamakondi et al., 2014). The percentage growth inhibition was calculated using the following formula and concentration of test drug needed to inhibit cell growth by $50 \%\left(\mathrm{CTC}_{50}\right)$ values is generated from the doseresponse curves for each cell line. The experiments were performed in triplicate.

Growth Inhibiton $(\%)=100-\left\{\frac{\text { Mean optical density of test }}{\text { Mean optical density of control }}\right\} \times 100$

\section{Stability Studies}

Stability study was performed as per International Conference on Harmonisation guidelines Q1A(R2) to assess the prepared hydrophobic drug loaded polymeric nanoformulation for its stability and potential to withstand atmospheric/environmental changes. Prepared plain and Camptothecin loaded polymeric nanoformulation were packed in a clear glass vial and stored at long term condition $\left(25^{\circ} \mathrm{C} \pm 2{ }^{\circ} \mathrm{C} / 60 \% \mathrm{RH} \pm 5 \% \mathrm{RH}\right)$ for 12 months and accelerated stability condition $\left(40^{\circ} \mathrm{C} \pm 2{ }^{\circ} \mathrm{C} / 75 \% \mathrm{RH} \pm\right.$ $5 \% \mathrm{RH}$ ) for 6 months in a stability chamber (SS134, Shivani Scientific). The samples were evaluated at time intervals of 3 months. The stored samples were analysed for average particle size, particle size uniformity, surface area, zeta potential, drug content and drug release (Ahmed Abd El-Bary et al., 2012). The experiments were performed in triplicate.

\section{RESULTS AND DISCUSSION}

\section{Fabrication of plain and Camptothecin loaded polymeric nanoparticles}

Plain and Camptothecin loaded Poly (Methacyclic acidco-methyl-methyacrylate) nanoparticles were prepared based on the principle of nanoprecipitation under the influence of stirring. In nanoprecipitation method, the solvent stream contains Camptothecin and Poly (Methacyclic acid-co-methylmethyacrylate) in water miscible organic solvent dimethyl sulphoxide and anti-solvent stream contains poloxamer 188 as a surfactant and $\beta$ cyclodextrin as a stabilizer in water. Addition of solvent stream into the anti-solvent stream results in the miscibility of dimethyl sulphoxide with water, which leads to the increase in 
the polarity of dimethyl sulphoxide, which in turn decreases the solubility of polymer. However, nucleation of polymer gets initiated when the equilibrium concentration surpasses the solubility threshold of polymer. Stirring process aid the size reduction of polymer at the initial stage but in the later stages, anionic nature of polymer provided anionic charge to the nanoparticle surface and higher number of likely charged nanoparticles repels each other and creates an electrostatic repulsive force and maintains the nanoparticles in Brownian motion, which is expected to overcome the van der walls attractive force arising from induced dipole-dipole interaction between nanoparticles and gravitational force, thereby stabilize the nanoformulation by preventing the aggregation.

\section{Average particle size, Particle size uniformity, Surface area and Zeta potential analysis}

After fabrication, prepared plain and Camptothecin loaded polymeric nanoparticles were stored at room temperature for one month to identify any aggregation and post-formulation degradation. Prepared plain and Camptothecin loaded polymeric nanoparticles were characterized for average particles size, particle size uniformity, surface area and zeta potential as per the procedure mention above. The results were summarized in table 3 and characterization spectrums were displayed in figure 1 and figure 2 .
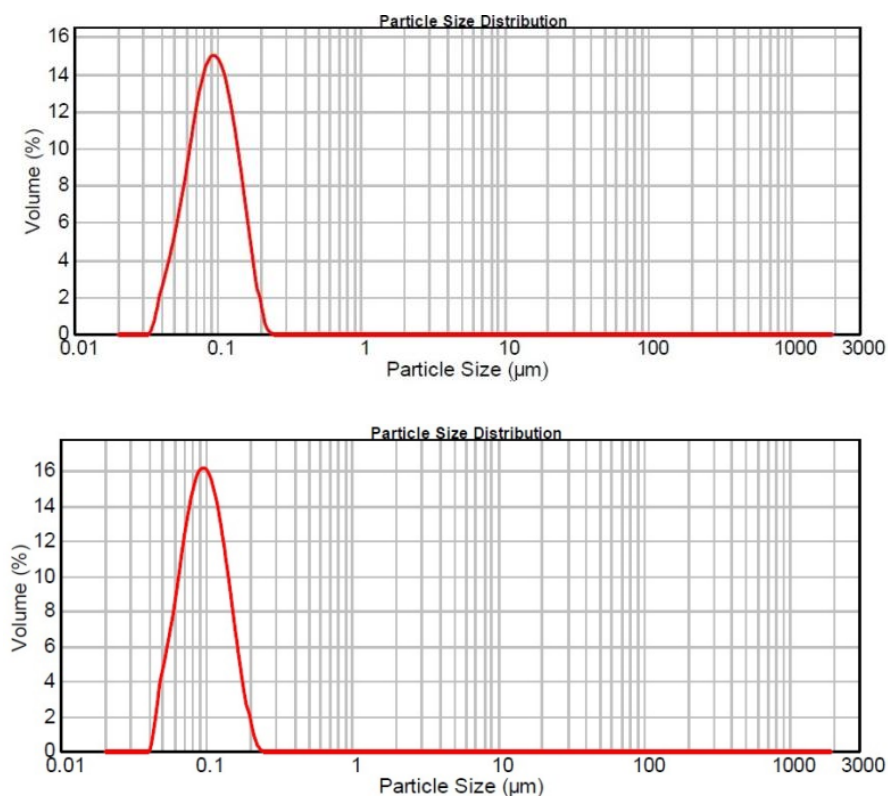

Fig. 1: Particle size spectrum of Plain (a) and Camptothecin (b) loaded polymeric nanoparticles.

After fabrication, prepared plain and Camptothecin loaded polymeric nanoparticles were stored at room temperature for one month. However, there was no visual aggregation and post formulation degradation. In stirring technique, plain polymeric nanoparticles has shown an average particle size of $97 \mathrm{~nm}$, particle size uniformity of 0.268 , surface area of $74.2 \mathrm{~m}^{2} \mathrm{~g}^{-1}$ and zeta potential of - $28.5 \mathrm{mV}$. Nevertheless, encapsulation of
Camptothecin has increased the average particle size to $100 \mathrm{~nm}$, decreased particle size uniformity to 0.242 , decreased the surface are to $65.2 \mathrm{~m}^{2} \mathrm{~g}^{-1}$ and decreased the zeta potential to $-22.41 \mathrm{mV}$ respectively. After encapsulation of Camptothecin, average particle size increased due to the accommodation of drug in polymeric nanoparticles. Average particle size $\leq 100 \mathrm{~nm}$, particle size uniformity $<0.3$, surface area $>50 \mathrm{~m}^{2} \mathrm{~g}^{-1}$ and zeta potential $>$ $20 \mathrm{mV}$ were set as acceptance criteria (Feng-Lin Yen et al., 2010). However, Camptothecin loaded nanoparticles prepared by stirring method satisfied all acceptance criteria.

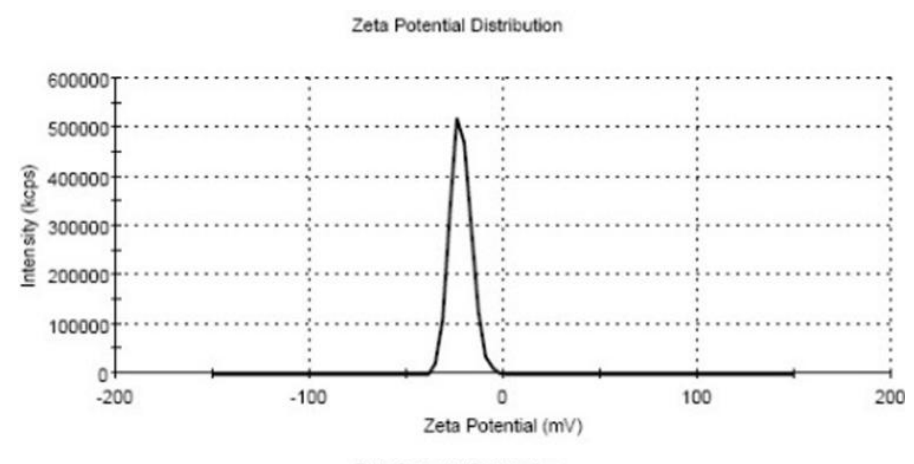

Zeta Potential Distribution

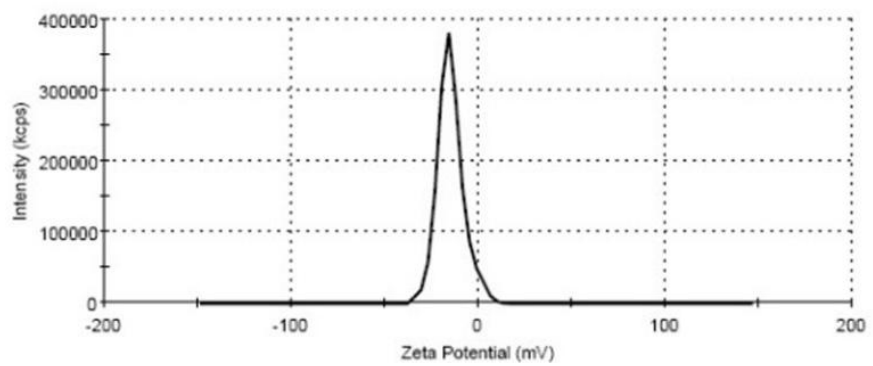

Fig. 2: Zeta potential spectrum of plain (a) and Camptothecin (b) loaded polymeric nanoparticles.

Table 3: Average particle size, particle size uniformity, surface area and zeta potential analysis of plain and Camptothecin loaded polymeric nanoparticles.

\begin{tabular}{ccccc} 
Trails & $\begin{array}{c}\text { Average particle } \\
\text { size }(\mathbf{n m})\end{array}$ & $\begin{array}{c}\text { Particle Size } \\
\text { Uniformity }\end{array}$ & $\begin{array}{c}\text { Surface } \\
\text { Area } \\
\left(\mathbf{m}^{2} \mathbf{g}^{-1} \pm \mathbf{S D}\right)\end{array}$ & $\begin{array}{c}\text { Zeta Potential } \\
(\mathbf{m V})\end{array}$ \\
\hline Plain & $97 \pm 0.18$ & $0.268 \pm 0.11$ & $74.2 \pm 0.19$ & $-28.5 \pm 1.25$ \\
CPT & $100 \pm 0.25$ & $0.242 \pm 0.04$ & $65.2 \pm 0.39$ & $-22.4 \pm 1.36$ \\
\hline \multicolumn{5}{l}{ The values are expressed as Mean $\pm \mathrm{SD} ; \mathrm{n}=3 ;$} \\
\end{tabular}

\section{Particle surface morphology analysis}

Particle surface morphology decides the basic function of particle degradation, release of drug from polymer matrix, transport of particles in the body, internalization of drug. The surface morphology analysis for the prepared plain and Camptothecin loaded polymeric nanoparticles were performed by field emission scanning electron microscopy (FESEM) and transmission electron microscopy (TEM) as per the procedure mentioned above and the TEM images were displayed in figure 3 $\& 4$ as well as the FESEM images were displayed in figure $5 \& 6$. Prepared Camptothecin loaded polymeric nanoparticles were spherical in shape. Hence, Camptothecin encapsulated in the polymer matrix will also be in spherical shape and expected to 
enhance the basic function, release of Camptothecin from the polymer matrix, transport of Camptothecin in the body and internalization of Camptothecin by many folds than the free Camptothecin.

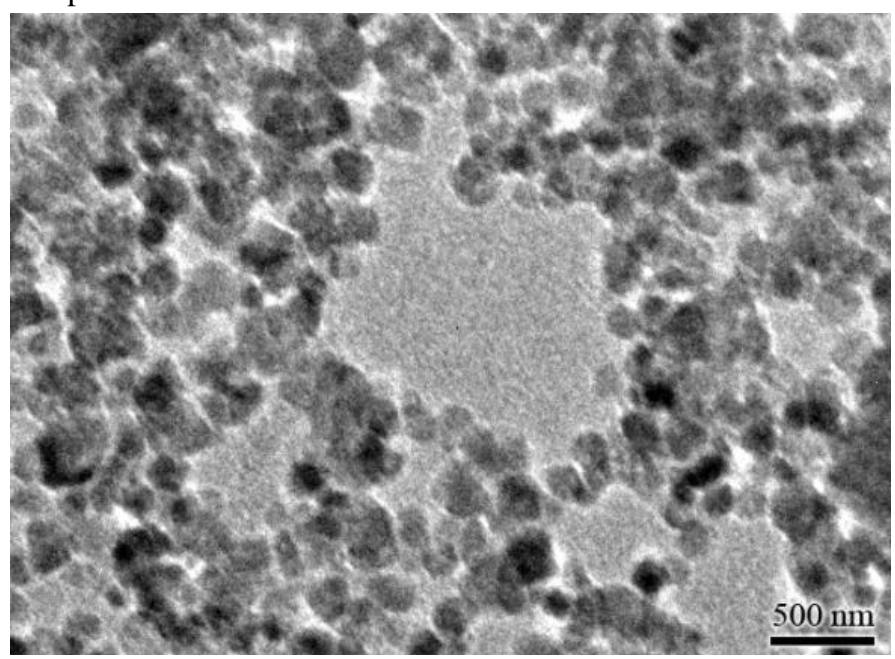

Fig. 3: TEM image of plain polymeric nanoparticles.

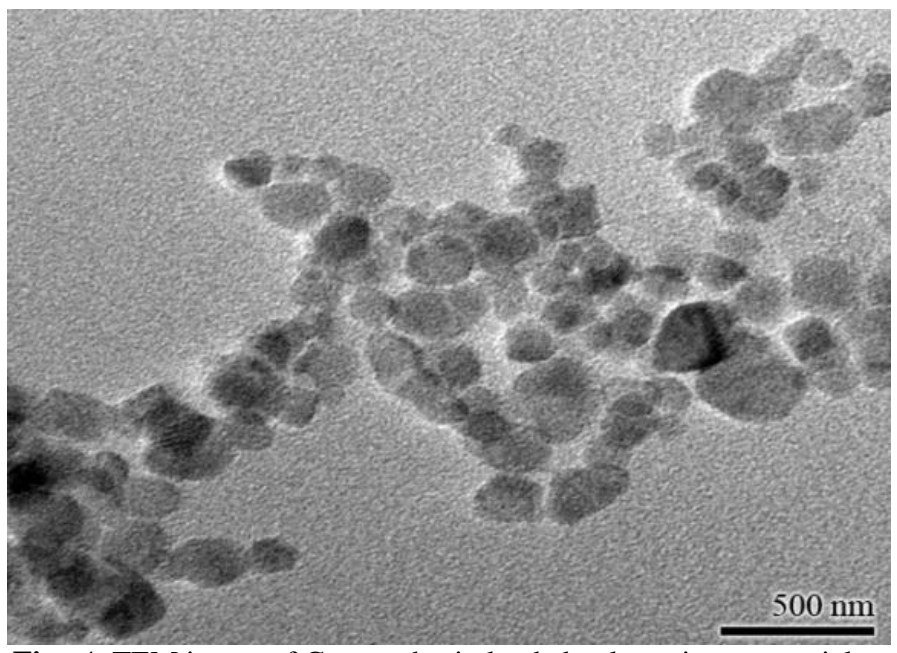

Fig. 4: TEM image of Camptothecin loaded polymeric nanoparticles

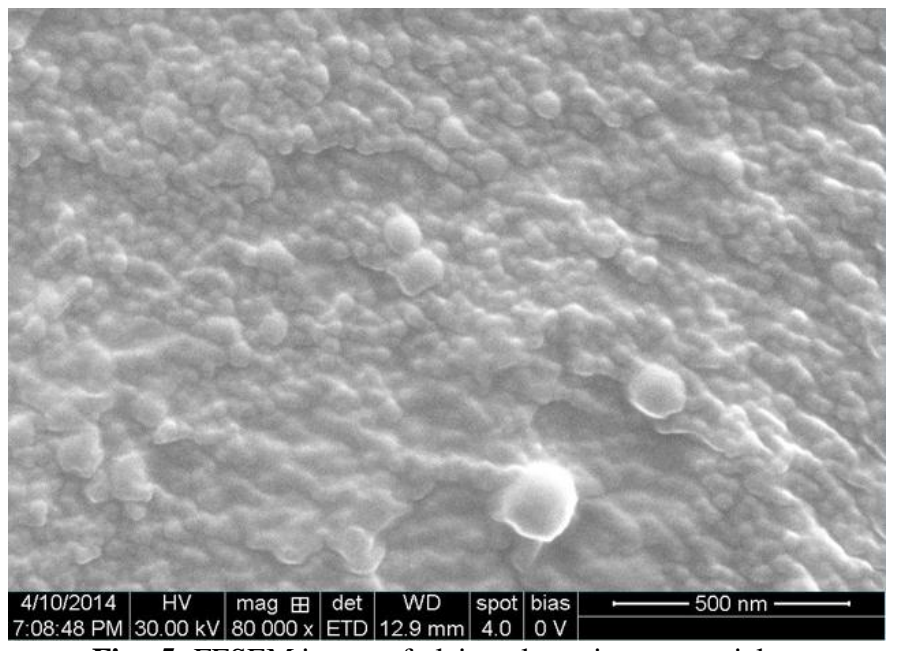

Fig. 5: FESEM image of plain polymeric nanoparticles.

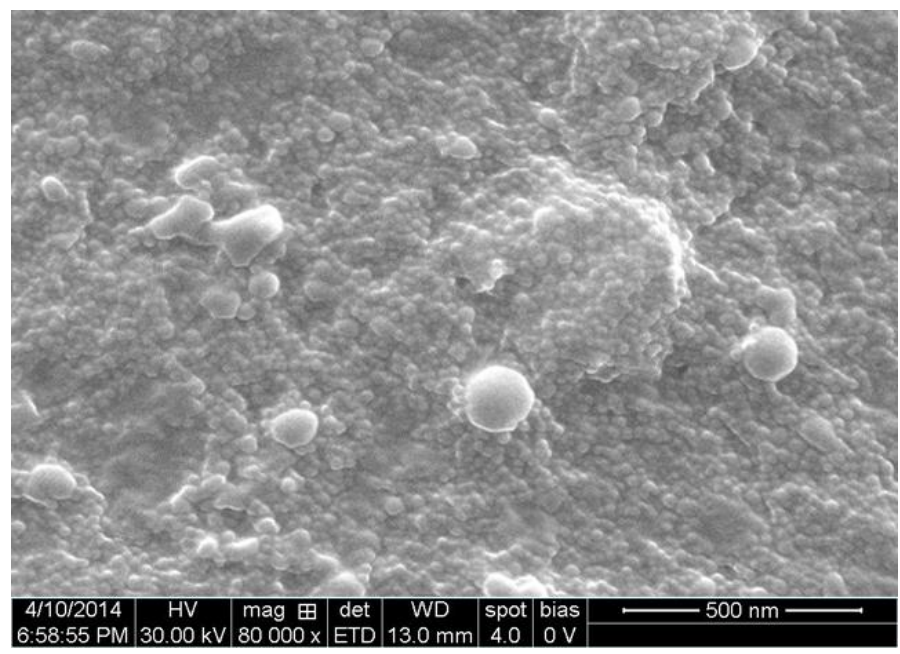

Fig. 6: FESEM image of Camptothecin loaded polymeric nanoparticles.

\section{Drug content, encapsulation efficiency \& drug loading estimation}

The amount of Camptothecin encapsulated in polymeric nanoparticles determines the effectiveness of prepared nanoformulations. Hence, drug content, encapsulation efficiency and drug loading estimation were performed as per procedure mentioned above. Drug content was estimated by performing an assay whereas encapsulation efficiency and drug loading were calculated by measuring the free Camptothecin in the nanoformulation. The results were summarized in table 4 .

Table. 4: Drug Content, Encapsulation efficiency and Drug loading of the prepared Camptothecin loaded polymeric nanoparticles.

\begin{tabular}{cccc}
\hline Trial & $\begin{array}{c}\text { Drug content } \\
(\boldsymbol{\%})\end{array}$ & $\begin{array}{c}\text { Encapsulation } \\
\text { efficiency }(\boldsymbol{\%})\end{array}$ & $\begin{array}{c}\text { Drug loading } \\
(\boldsymbol{\%})\end{array}$ \\
CPT & $97.96 \pm 0.59$ & $93.17 \pm 0.72$ & $9.13 \pm 0.38$ \\
\hline \multicolumn{4}{l}{ The values are expressed as Mean $\pm \mathrm{SD} ; \mathrm{n}=3 ;$}
\end{tabular}

Drug content in the formulations was in the range of 96 to 100 , which shows that there was no post-formulation degradation or drug loss. The drug content, encapsulation efficiency and drug loading of the prepared Camptothecin loaded polymeric nanoparticles were found to be $97.96 \%, 93.17 \%$ and 9.13\% respectively. The stirring approach displayed excellent encapsulation efficiency and drug loading only insignificant amount of Camptothecin were seen as free drug. Hence, prepared Camptothecin loaded polymeric nanoparticles is expected to display superior pharmacological activities.

\section{In vitro drug release study}

In vitro drug release from the Camptothecin loaded polymeric nanoparticles prepared by nanoprecipitation method using stirring approach was assessed in simulated gastrointestinal conditions. The $\mathrm{pH}$ condition used was $\mathrm{pH} 1.2$ for a period of $2 \mathrm{hrs}$ (stomach), $\mathrm{pH} 4.5$ for $2 \mathrm{hrs}$ (duodenum) followed by $\mathrm{pH} 7.4$ (distal ileum and colon) for the remaining period of the study using a USP dissolution test apparatus (Apparatus type 2) (Chandran et al., 2009) and in vitro drug release were shown in figure 7 . The 
drug release was found to be less than $5 \%$ upto $4 \mathrm{hrs}$ and the drug release increased when the $\mathrm{pH}$ of the medium was adjusted to 7.4. Poly (Methacyclic acid-co-methyl-methyacrylate) is an anionic polymer, the ratio of free carbonyl groups to the ester groups is approximately 1:2. It exhibits a dissolution threshold $\mathrm{pH}$ slightly above 7.2 (Sinha and Kumari, 2003). Due to the $\mathrm{pH}$ sensitive property, it was selected to avoid the rapid dissolution of Camptothecin during the initial transit of the nanoparticles through gastric cavity and the upper small intestine. It was observed that polymer coated Camptothecin nanoparticles gave no release in the simulated gastric fluid, negligible release in the simulated intestinal fluid and maximum release in the colonic environment. Hence, released nanosized Camptothecin are expected to display enhanced aqueous solubility and permeability in the colon.

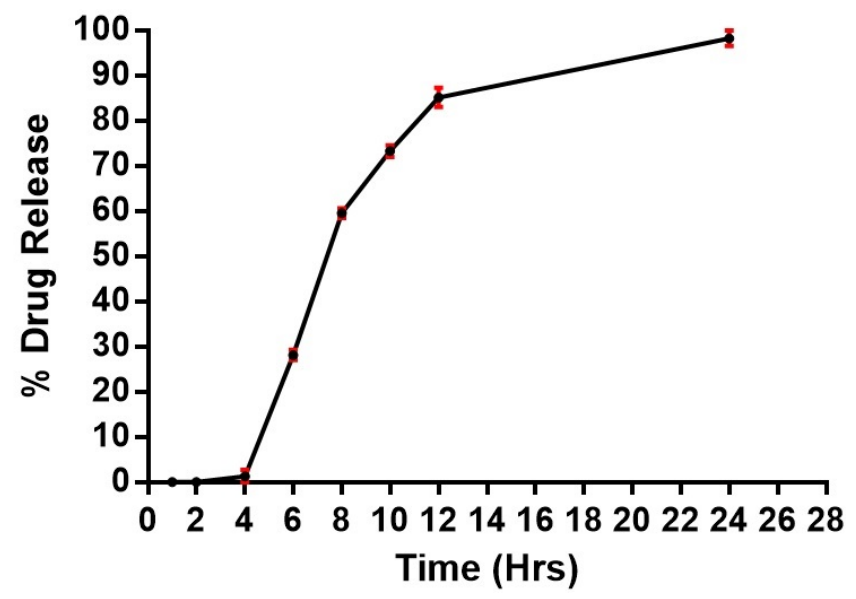

Fig. 7: In vitro release profile of Camptothecin from prepared polymeric nanoparticles.

\section{Kinetics Analysis}

The results of in vitro release profile obtained from the formulations were plotted to know the mechanism of drug release. The data were treated according to zero order release, first order release, higuchi model, korsemeyer peppas model and hixson crowell cube root law. The release rate kinetics data of the formulation is shown in table 5 .

Table 5: Determination coefficients $\left(r^{2}\right)$ and release exponent (n) of kinetic data analysis of Camptothecin release from polymeric nanoparticles.

\begin{tabular}{lllllll}
\hline Trial & $\begin{array}{l}\text { Zero } \\
\text { order } \\
\mathbf{r}^{2}\end{array}$ & $\begin{array}{l}\text { First } \\
\text { Order } \\
\mathbf{r}^{2}\end{array}$ & $\begin{array}{l}\text { Higuchi } \\
\text { model } \\
\mathbf{r}^{2}\end{array}$ & $\begin{array}{l}\text { Korsmeyer-peppas } \\
\text { model }\end{array}$ & $\begin{array}{l}\text { Hixson- } \\
\text { crowell } \\
\text { cube root } \\
\text { law } \mathbf{r}^{2}\end{array}$ \\
\hline CPT & 0.7211 & 0.7157 & 0.6255 & 0.546 & 1.5289 & 0.9452 \\
\hline
\end{tabular}

It is concluded that the Camptothecin loaded polymeric nanoparticles prepared by nanoprecipitation method using stirring approach gave a good fit to the hixson crowell cube root law. The diffusion exponent (n) value were greater than 0.89 , this result indicated that the release of drug from the polymer matrix formulations was found to be super case-II transport, i. e., drug release by both diffusion and relaxation of polymer chain.

\section{In vitro anticancer activity}

Prepared Camptothecin loaded polymeric nanoformulation was studied for its in vitro anticancer efficacy against human colon cancer HT-29 cell line and the results were summarised in table 6 and figure 8 .

Pure Camptothecin displayed very poor anticancer activity on HT-29 cell at $1000 \mu \mathrm{g} / \mathrm{ml}\left(\mathrm{CTC}_{50}\right.$ : $\left.>1000 \mu \mathrm{g} / \mathrm{ml}\right)$. Camptothecin loaded polymeric nanoformulation displayed good anticancer activity on HT-29 cells at $1000 \mu \mathrm{g} / \mathrm{ml}\left(\mathrm{CTC}_{50}: 170.00\right.$ $\mu \mathrm{g} / \mathrm{ml})$. However, prepared Camptothecin loaded polymeric nanoformulations displayed enhanced anticancer activity against HT-29 cells in comparison with pure Camptothecin.

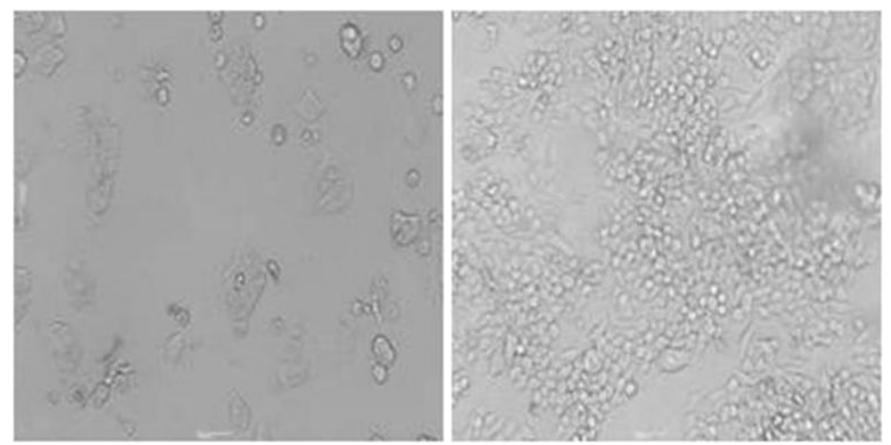

Fig. 8: In vitro anti cancer activity of pure Camptothecin (a) and Camptothecin loaded polymeric nanoparticles (b) on HT-29 cells.

Table 6: In vitro anticancer activity of prepared Camptothecin loaded polymeric Nanoparticles on HT-29 cells.

\begin{tabular}{lcccccc}
\hline Samples & \multicolumn{7}{c}{ Percentage control growth } \\
\cline { 2 - 7 } & $\mathbf{1 0 0 0}$ & $\mathbf{5 0 0}$ & $\mathbf{2 5 0}$ & $\mathbf{1 2 5}$ & $\mathbf{6 2 . 5}$ & $\mathbf{C T C}_{\mathbf{5 0}}$ \\
& $(\boldsymbol{\mu g} / \mathbf{M l})$ & $(\boldsymbol{\mu g} / \mathbf{M I})$ & $(\boldsymbol{\mu g} / \mathbf{M l})$ & $(\boldsymbol{\mu g} / \mathbf{M l})$ & $(\boldsymbol{\mu g} / \mathbf{M l})$ & $(\boldsymbol{\mu g} / \mathbf{M I})$ \\
\hline Pure Camptothecin & 20.18 & 16.21 & 14.12 & 12.24 & 9.57 & $>1000$ \\
& \pm 0.24 & \pm 0.29 & \pm 0.25 & \pm 0.19 & \pm 0.15 & \\
Camptothecin loaded & 95.62 & 85.66 & 57.77 & 45.00 & 44.9 & $170.00 \pm$ \\
polymeric nano- & \pm 1.7 & \pm 0.7 & \pm 0.7 & \pm 0.68 & $5 \pm 1.3$ & 0.7 \\
formulation & & & & & & \\
\hline
\end{tabular}

The values are expressed as Mean \pm SD; $n=3$.

\section{Stability studies}

Prepared plain and Camptothecin loaded polymeric nanoformulation were subjected to stability studies as per the mentioned above. At the regular intervals the stored samples were evaluated for average particle size, particle size uniformity, surface area, zeta potential, drug content and drug release. The results were summarized in table 7 - 10.

Prepared plain and Camptothecin loaded polymeric nanoparticles showed insignificant change in average particle size, particle size uniformity, surface area, zeta potential, drug content and drug release after stability storage at both long term and accelerated conditions. 
Table 7: Average particle size, particle size uniformity, surface area, zeta potential and drug content estimation of prepared polymeric nanoparticles subjected to long term stability study as per ICH guidelines $\left(25^{\circ} \mathrm{C} \pm 2^{\circ} \mathrm{C} / 60 \% \mathrm{RH} \pm 5 \% \mathrm{RH}\right)$

\begin{tabular}{|c|c|c|c|c|c|c|}
\hline Trials & $\begin{array}{c}\text { Period } \\
\text { (Months) }\end{array}$ & $\begin{array}{c}\text { Average particle } \\
\text { size }(\mathbf{n m})\end{array}$ & $\begin{array}{c}\text { Particle Size } \\
\text { Uniformity }\end{array}$ & $\begin{array}{c}\text { Surface Area } \\
\left(\mathrm{m}^{2} \mathrm{~g}^{-1} \pm \mathrm{SD}\right)\end{array}$ & $\begin{array}{c}\text { Zeta Potential } \\
(\mathrm{mV})\end{array}$ & $\begin{array}{c}\text { Drug } \\
\text { Content }(\%)\end{array}$ \\
\hline \multirow[t]{3}{*}{ Plain } & 0 & $97 \pm 0.18$ & $0.268 \pm 0.11$ & $74.20 \pm 0.19$ & $-28.5 \pm 1.25$ & - \\
\hline & $3^{\text {rd }}$ & $98 \pm 0.61$ & $0.270 \pm 0.71$ & $74.80 \pm 0.63$ & $-28.1 \pm 0.78$ & - \\
\hline & $6^{\text {th }}$ & $99 \pm 0.93$ & $0.279 \pm 0.58$ & $75.06 \pm 0.93$ & $-27.8 \pm 0.43$ & - \\
\hline \multirow[t]{3}{*}{ CPT } & 0 & $100 \pm 0.25$ & $0.242 \pm 0.04$ & $65.2 \pm 0.39$ & $-22.4 \pm 1.36$ & $97.86 \pm 0.98$ \\
\hline & $3^{\text {rd }}$ & $101 \pm 0.59$ & $0.245 \pm 0.55$ & $64.9 \pm 0.55$ & $-21.9 \pm 1.23$ & $97.15 \pm 1.24$ \\
\hline & $6^{\text {th }}$ & $101 \pm 0.61$ & $0.249 \pm 0.73$ & $64.1 \pm 0.43$ & $-21.4 \pm 1.24$ & $96.89 \pm 1.19$ \\
\hline
\end{tabular}

The values are expressed as Mean $\pm \mathrm{SD} ; \mathrm{n}=3$;

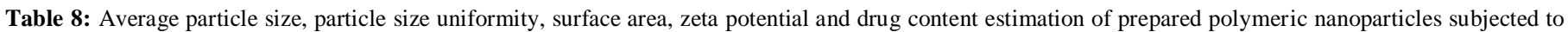
accelerated stability study as per ICH guidelines $\left(40^{\circ} \mathrm{C} \pm 2{ }^{\circ} \mathrm{C} / 75 \% \mathrm{RH} \pm 5 \% \mathrm{RH}\right)$.

\begin{tabular}{|c|c|c|c|c|c|c|}
\hline Trials & $\begin{array}{c}\text { Period } \\
\text { (Months) } \\
\end{array}$ & $\begin{array}{c}\text { Average particle } \\
\text { size }(\mathbf{n m})\end{array}$ & $\begin{array}{c}\text { Particle Size } \\
\text { Uniformity }\end{array}$ & $\begin{array}{c}\text { Surface Area } \\
\left(\mathrm{m}^{2} \mathrm{~g}^{-1} \pm \mathrm{SD}\right)\end{array}$ & $\begin{array}{c}\text { Zeta Potential } \\
(\mathrm{mV})\end{array}$ & $\begin{array}{c}\text { Drug } \\
\text { Content }(\%) \\
\end{array}$ \\
\hline \multirow[t]{3}{*}{ Plain } & 0 & $97 \pm 0.18$ & $0.268 \pm 0.11$ & $74.2 \pm 0.19$ & $-28.5 \pm 1.25$ & - \\
\hline & $3^{\mathrm{rd}}$ & $97 \pm 0.25$ & $0.271 \pm 0.15$ & $75.12 \pm 0.26$ & $-27.1 \pm 0.84$ & - \\
\hline & $6^{\text {th }}$ & $99 \pm 0.61$ & $0.284 \pm 0.19$ & $75.02 \pm 0.35$ & $-27.2 \pm 0.57$ & - \\
\hline \multirow[t]{3}{*}{ CPT } & 0 & $100 \pm 0.25$ & $0.242 \pm 0.04$ & $65.2 \pm 0.39$ & $-22.4 \pm 1.36$ & $97.86 \pm 1.67$ \\
\hline & $3^{\text {rd }}$ & $100 \pm 0.35$ & $0.246 \pm 0.41$ & $64.1 \pm 0.26$ & $-22.1 \pm 1.20$ & $97.35 \pm 1.42$ \\
\hline & $6^{\text {th }}$ & $101 \pm 0.64$ & $0.251 \pm 0.24$ & $63.9 \pm 0.12$ & $-21.2 \pm 0.98$ & $96.80 \pm 1.26$ \\
\hline
\end{tabular}

The values are expressed as Mean $\pm \mathrm{SD} ; \mathrm{n}=3$;

Table 9: In vitro release profile of Camptothecin from the prepared polymeric nanoparticles subjected to subjected to long term stability study as per ICH guidelines $\left(25^{\circ} \mathrm{C} \pm 2{ }^{\circ} \mathrm{C} / 60 \% \mathrm{RH} \pm 5 \% \mathrm{RH}\right)$.

\begin{tabular}{|c|c|c|c|c|c|}
\hline Periods & 0 Months & 3 Months & 6 Months & 9 Months & 12 Months \\
\hline 0 hour & 0 & 0 & 0 & 0 & 0 \\
\hline 1 hour & 0 & 0 & 0 & 0 & 0 \\
\hline 2 hour & 0 & 0 & 0 & 0 & 0 \\
\hline 4 hour & $1.28 \pm 1.40$ & $1.25 \pm 0.34$ & $1.22 \pm 0.49$ & $1.19 \pm 0.67$ & $1.24 \pm 0.37$ \\
\hline 6 hour & $28.14 \pm 1.12$ & $27.89 \pm 1.31$ & $28.01 \pm 0.78$ & $27.69 \pm 1.26$ & $27.51 \pm 1.37$ \\
\hline 8 hour & $59.55 \pm 1.09$ & $59.10 \pm 1.86$ & $58.94 \pm 1.67$ & $58.54 \pm 1.43$ & $57.25 \pm 1.29$ \\
\hline 10 hour & $73.25 \pm 1.26$ & $72.84 \pm 1.67$ & $72.12 \pm 1.59$ & $71.96 \pm 1.46$ & $71.32 \pm 1.47$ \\
\hline 12 hour & $85.14 \pm 2.14$ & $85.01 \pm 1.83$ & $84.78 \pm 1.37$ & $84.23 \pm 1.51$ & $83.87 \pm 1.79$ \\
\hline 24 hour & $98.22 \pm 1.71$ & $98.01 \pm 2.45$ & $97.78 \pm 2.19$ & $97.20 \pm 2.37$ & $97.06 \pm 2.57$ \\
\hline
\end{tabular}

The values are expressed as Mean $\pm \mathrm{SD} ; \mathrm{n}=3$;

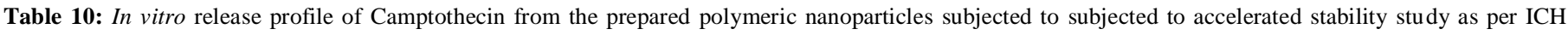
guidelines $\left(40^{\circ} \mathrm{C} \pm 2{ }^{\circ} \mathrm{C} / 75 \% \mathrm{RH} \pm 5 \% \mathrm{RH}\right)$.

\begin{tabular}{|c|c|c|c|}
\hline Periods & ( M Months & 3 Months & 6 Months \\
\hline 0 hour & 0 & 0 & 0 \\
\hline 1 hour & 0 & 0 & 0 \\
\hline 2 hour & 0 & 0 & 0 \\
\hline 4 hour & $1.28 \pm 1.40$ & $1.23 \pm 0.54$ & $1.29 \pm 0.65$ \\
\hline 6 hour & $28.14 \pm 1.12$ & $27.74 \pm 1.12$ & $28.12 \pm 0.64$ \\
\hline 8 hour & $59.55 \pm 1.09$ & $59.54 \pm 1.72$ & $58.82 \pm 1.42$ \\
\hline 10 hour & $73.25 \pm 1.26$ & $72.72 \pm 1.94$ & $72.02 \pm 1.26$ \\
\hline 12 hour & $85.14 \pm 2.14$ & $85.06 \pm 1.74$ & $84.81 \pm 1.23$ \\
\hline 24 hour & $98.22 \pm 1.71$ & $98.21 \pm 2.62$ & $97.54 \pm 2.45$ \\
\hline
\end{tabular}

The values are expressed as Mean $\pm \mathrm{SD} ; \mathrm{n}=3$;

\section{CONCLUSION}

A novel $\mathrm{pH}$ sensitive polymeric nanoparticle of a hydrophobic drug Camptothecin was prepared by nanoprecipitation method with stirring technique. Prepared plain and Camptothecin loaded polymeric nanoparticles were characterized for average particle size, particle size uniformity, surface area and zeta potential. Nanoparticles prepared using stirring method was with average particles of $<100 \mathrm{~nm}$, uniformity of $<0.3$ and zeta potential of $>20 \mathrm{mV}$. Prepared Camptothecin loaded polymeric nanoparticles were spherical in shape. Hence, Camptothecin encapsulated in the polymer matrix will also be in spherical shape and expected to enhance the basic function, release of Camptothecin from the polymer matrix, transport of Camptothecin in the body and internalization of Camptothecin by many folds than the free Camptothecin. Stirring approach displayed excellent encapsulation efficiency and drug loading and only an insignificant amount of Camptothecin were seen as a free drug. Hence, prepared Camptothecin loaded polymeric nanoparticles is expected to display superior pharmacological activities. It was observed that Poly (Methacyclic acid-co-methyl-methyacrylate) coated Camptothecin nanoparticles gave no release in the simulated gastric fluid, negligible release in the simulated intestinal fluid and maximum release in the colonic environment. It is concluded that the formulation gave a good fit to the Hixson Crowell cube root law. Prepared Camptothecin loaded polymeric nanoparticles were studied for its in vitro anticancer efficacy against human colon cancer cells using MTT assay. 
Prepared Camptothecin loaded polymeric nanoformulations displayed enhanced anti cancer activity against HT-29 cells in comparison with pure Camptothecin. Thus, the results indicate the potential for in vivo studies of the developed $\mathrm{pH}$ sensitive polymeric nanoparticles of a hydrophobic drug Camptothecin to establish their clinical application. The prepared plain and dual drug loaded nanoformulation were subjected to stability studies at $25^{\circ} \mathrm{C} \pm 2{ }^{\circ} \mathrm{C} / 60 \% \mathrm{RH} \pm 5 \% \mathrm{RH}$ for 112 months and $40{ }^{\circ} \mathrm{C} \pm$ $2^{\circ} \mathrm{C} / 75 \% \mathrm{RH} \pm 5 \% \mathrm{RH}$ for 6 months. At the end of the storage period, it showed insignificant changes in average particle size, particle size uniformity, surface area, zeta potential, drug content and drug release. In summary, the investigation concluded that the prepared Camptothecin encapsulated polymeric nanoformulations may be considered as an attractive and promising formulation which significantly overcome the limitations of Camptothecin in the treatment of colon cancer and synergistically enhance its anticancer activity.

\section{ACKNOWLEDGEMENT}

The authors are thankful to UGC, Government of India, for providing UGC-BSR Fellowship.

\section{CONFLICTS OF INTEREST}

The authors declare that there are no conflicts of interest.

\section{REFERENCES}

Ahmed Abd El-Bary, Ahmed A. Aboelwafa, Ibrahim M. Al Sharabi. Influence of some formulation variables on the optimization of pH-dependent, colon-targeted, sustained-release Mesalamine microspheres. AAPS PharmSciTech, 2012; 13(1):75-84.

Alexis F, Rhee JW, Richie JP, Radovic-Moreno AF, Robert Langer R, Farokhzad OC. New frontiers in nanotechnology for cancer treatment. Urol Oncol, 2008; 26(1):74-85.

Amir H. Faraji, Peter Wipf. Nanoparticles in cellular drug delivery. Bioorg Med Chem, 2009; 17(8):2950-62.

Bo Xiao, Mingzhen Zhang, Emilie Viennois, Yuchen Zhang, Na Wei, Mark T. Baker, Yunjin Jung, Didier Merlin. Inhibition of MDR1 gene expression and enhancing cellular uptake for effective colon cancer treatment using dual-surface-functionalized nanoparticles. Biomater, 2015; 48:147-60.

Catarina Goncalves, Paula Pereira, Miguel Gama. SelfAssembled Hydrogel Nanoparticles for Drug Delivery Applications. Mater, 2010; 3(2):1420-60.

Champion JA, Yogesh K. Katare, Samir Mitragotri. Particle shape: A new design parameter for micro- and nanoscale drug delivery carriers. J Control Release, 2007; 121(1-2):3-9.

Chandran S, Sanjay KS, Ali Asghar LF. Microspheres with $\mathrm{pH}$ modulated release: Design and characterization of formulation variables for colonic delivery. J Microencapsul, 2009; 26(5):420-31.

Danhier F, Feron O, Preat V. To exploit the tumor microenvironment: Passive and active tumor targeting of nanocarriers for anti-cancer drug delivery. J Control Release, 2010; 148(2):135-46.

Eliana Leo, Barbara Brina, Flavio Forni, Maria Angela Vandelli. In vitro evaluation of PLA nanoparticles containing a lipophilic drug in water-soluble or insoluble form. Int J Pharm, 2004; 278(1):133-41.

Emilie Secret, Kevin Smith, Valentina Dubljevic, Eli Moore, Peter Macardle, Bahman Delalat, Mary-Louise Rogers, Terrance G. Johns, Jean-Olivier Durand, Frederique Cunin, Nicolas H. Voelcker. Antibody-
Functionalized Porous Silicon Nanoparticles for Vectorization of Hydrophobic Drugs. Adv Healthc Mater, 2013; 2(5):718-27.

Eun-Kyung Lim, Warayuth Sajomsang, Yuna Choi, Eunji Jang, Hwunjae Lee, Byunghoon Kang, Eunjung Kim, SeungjooHaam, Jin-Suck Suh, Sang Jeon Chung, Yong-Min Huh. Chitosan-based intelligent theragnosis nanocomposites enable $\mathrm{pH}$-sensitive drug release with MRguided imaging for cancer therapy. Nanoscale Res Lett, 2013; 8(1):1-12.

Feng-Lin Yen, Tzu-Hui Wu, Cheng-Wei Tzeng, Liang-Tzung Lin, Chun Ching Lin. Curcumin nanoparticles improve the physicochemical properties of curcumin and effectively enhance its antioxidant and antihepatoma activities. J Agric Food Chem, 2010; 58(12):7376-82

Francis D, Rita L. Rapid colorometric assay for cell growth and survival modifications to the tetrazolium dye procedure giving improved sensitivity and reliability. J Immunol Methods, 1986; 89(2):271-7.

Galindo-Rodriguez S, Allemann E, Fessi H, Doelker E. Physicochemical parameters associated with nanoparticle formation in the salting out, emulsification-diffusion, and nanoprecipitation methods. Pharm Res, 2004; 21(8):1428-39.

Giftson Senapathy J, Jayanthi S, Viswanathan P, Umadevi P, Nalini N. Effect of gallic acid on xenobiotic metabolizing enzymes in 1,2dimethyl hydrazine induced colon carcinogenesis in Wistar rats - A chemopreventive approach. Food Chem Toxicol, 2011; 49(4):887-92.

Gregory Morose. The 5 principles of Design for Safer Nanotechnology. J Clean Prod, 2010; 18(3):285-89.

Hadjiioannou TP, Christian GD, Koupparis MA, Macheras PE, 1993. Biopharmaceutics and Drug Disposition. In. Quantitative Calculations in Pharmaceutical Practice and Research. New York: VCH Publishers Inc 345-8.

Harivardhan Reddy L, Murthy RSR. Etoposide-loaded nanoparticles made from glyceride lipids: formulation, characterization, in vitro drug release, and stability evaluation. AAPS PharmSciTech, 2005; 6 (2):E158-66.

Harris Shoaib M, JaweriaTazeen, Hamid A. Merchant, Rabia Ismail Yousuf. Evaluation of drug release kinetics from ibuprofen matrix tablets using HPMC. Pak J Pharm Sci, 2006; 19(2):119-24.

Higuchi T. Mechanism of sustained action medication. Theoretical analysis of rate of release of solid drugs dispersed in solid matrices. J Pharm Sci, 1963; 52:1145-9.

Hixson AW, Crowell JH. Dependence of reaction velocity upon surface and agitation (I) theoretical consideration. Ind Eng Chem, 1931; 23(8):923-31.

Hui Xie, Jeffrey W Smith. Fabrication of PLGA nanoparticles with a fluidic nanoprecipitation system. J Nanobiotechnology, 2010; 8:1-7.

Ji-Yao Zhang, Zhi-Gang Shen, Jie Zhonga, Ting-Ting Hub, Jian-Feng Chena, Zhong-Qing Mac, Jimmy Yun. Preparation of amorphous cefuroxime axetil nanoparticles by controlled nanoprecipitation method without surfactants. Int J Pharm, 2006; 323(12):153-60.

Jose Mario Barichello, Mariko Morishita, Kozo Takayama, Tsuneji Nagai. Encapsulation of Hydrophilic and Lipophilic Drugs in PLGA Nanoparticles by the Nanoprecipitation Method. Drug Dev Ind Pharm, 1999; 25(4):471-76.

Jung KY, Park BC, Song WY, O BH, Eom TB. Measurement of 100 -nm polystyrene sphere by transmission electron microscope. Powder Technol, 2002; 126(3):255-65.

Kannan K, Manikandan M, Periyasamy G, Manavalan R. Design, development and evaluation of metoprolol succinate and hydrochlorothiazide bilayer tablets. J Pharm Sci Res, 2012; 4(3):1827-35.

Karin Liltorp, Trine Gorm Larsenb, Birgitte Willumsenb, Rene Holma. Solid state compatibility studies with tablet excipients using non thermal Methods. J Pharm Biomed Anal, 2011; 55(3):424-8.

Korsmeyer RW, Gurny R, Doelker E, Buri P, Peppas NA. Mechanisms of solute release from porous hydrophilic polymers. Int $\mathbf{J}$ Pharm, 1983; 15(1):25-35.

Korsmeyer RW, Lustig SR, Peppas NA. Solute and penetrant diffusion in swellable polymers. I. Mathematical modeling. J Polym Sci Polym Phys, 1986a; 24(2):395-408. 
Luciano Aparecido Stecanella, Stephania Fleury Taveira, Ricardo Neves Marreto, Marize C. Valadares, Marcelo de Sousa Vieira, Massuo Jorge Kato, Eliana Martins Lima. Development and characterization of PLGA nanocapsules of grandisin isolated from Virolasurinamensis: in vitro release and cytotoxicity studies. Braz J Pharmacogn, 2013; 23(1):153-9.

Mahalingam Manikandan, Krishnamoorthy Kannan. Fabrication and optimization of Camptothecin loaded Eudragit S 100 nanoparticles by Taguchi L4 orthogonal array design. Int J Pharm Investig, 2015; 5(3):14754.

Mishra B, Bhavesh B. Patel, Sanjay Tiwari. Colloidal nanocarriers: a review on formulation technology, types and applications toward targeted drug delivery. Nanomed-Nanotech, 2010; 6(1):9-24.

Mohanty C, Sahoo SK. The in-vitro stability and in vivo pharmacokinetics of curcumin prepared as an aqueous nanoparticulate formulation. Biomater, 2010; 31(25):6597-611.

Muller RH, Jacobs C, Kayser O. Nanosuspensions as particulate drug formulations in therapy. Rationale for development and what we can expect for the future. Adv Drug Deliv Rev, 2001; 47(1):3-19.

Pandian P, Kannan K, Manikandan M, Manavalan R. Formulation and evaluation of oseltamivir phosphate capsules. Int J Pharm Pharm Sci, 2012; 4(4):342-7.

Pavan Kumar Bellamakondi, Ashok Godavarthi, Mohammed Ibrahim, Seetaram Kulkarni, Ramchandra Naik M, Maradam Sunitha. In vitro cytotoxicity of caralluma species by MTT and Trypan blue dye exclusion. Asian J Pharm Clin Res, 2014; 7(2):17-9.

Prabhu Rashmi H, Vandana B Patravale, Medha D Joshi. Polymeric nanoparticles for targeted treatment in oncology: current insights. Int J Nanomedicine, 2015; 10:1001-18.

Prakash K, Narayana Raju P, Shanta Kumari K, Lakshmi Narasu M. Solubility and dissolution rate determination of different antiretroviral drugs in different $\mathrm{pH}$ media using UV visible spectrophotometer. E-J Chem, 2008; 5(S2):1159-64.

Rajan K. Verma, Sanjay Garg. Selection of excipients for extended release formulations of glipizide through drug-excipient compatibility testing. J Pharm Biomed Anal, 2005; 38(4):633-44.

Ranjith K Averineni, Gopal V Shavi, Aravind K Gurram, Praful B Deshpande, Karthik Arumugam, Naseer Maliyakkal, Sreenivasa R Meka, Udupa Nayanabhirama. PLGA 50:50 nanoparticles of paclitaxel: Development, in vitro anti-tumor activity in BT-549 cells and in vivo evaluation. B Mater Sci, 2012; 35(3):319-26.
Seema Badhana, Navneet Garud, Akanksha Garud. Colon specific drug delivery of mesalamine using eudragit S100-coated chitosan microspheres for the treatment of ulcerative colitis. Int Curr Pharm J, $2013 ; 2(3): 42-8$.

Sinha R, Kim GJ, Nie S, Shin DM. Nanotechnology in cancer therapeutics: Bioconjugated nanoparticles for drug delivery. Mol Cancer Ther, 2006; 5(8):1909-17.

Sinha VR, Kumria R. Coating polymers for colon specific drug delivery: A comparative in vitro evaluation. Acta Pharm, 2003; 53(1):417.

Terzic J, Grivennikov S, Karin E, Karin M. Inflammation and colon cancer. Gastroenterol, 2010; 138(6):2101-14.

Thirumala Govender, Snjezana Stolnik, Martin C. Garnett, Lisbeth Illum, Stanley S. Davis. PLGA nanoparticles prepared by nanoprecipitation: drug loading and release studies of a water soluble drug. J Control Release, 1999; 57(2):171-85.

Torchilin V. Tumor delivery of macromolecular drugs based on the EPR effect. Adv Drug Deliv Rev, 2011; 63(3):131-5.

Uday S Rangole, Kawtikwar PS, Sakarkar DM. Formulation and in-vitro evaluation of rapidly disintegrating tablets using hydrochlorothiazide as a model drug. Research J Pharma and Tech, 2008; 1(4):349-52.

Varun Kumar, Robert K. Prud'homme. Nanoparticle stability: Processing pathways for solvent removal. Chem Eng Sci, 2009; 64(6):1358-61.

Yichao Wang, Puwang Li, Zheng Peng, Feng Hua She, Ling Xue Kong. Microencapsulation of nanoparticles with enhanced drug loading for $\mathrm{pH}$-sensitive oral drug delivery for the treatment of colon cancer. J Appl Polym Sci, 2013; 129(2):714-20.

\section{How to cite this article:}

Manikandan Mahalingam, Kannan Krishnamoorthy. Fabrication, Physicochemical Characterization and Evaluation of In vitro Anticancer Efficacy of a Novel pH Sensitive Polymeric Nanoparticles for Efficient Delivery of Hydrophobic Drug against Colon Cancer. J App Pharm Sci, 2015; 5 (11): 135-145. 